\title{
Recurrent Submandibular Gland Carcinoma
}

National Cancer Institute

\section{Source}

National Cancer Institute. Recurrent Submandibular Gland Carcinoma. NCI Thesaurus.

Code C153801.

The reemergence of submandibular gland carcinoma after a period of remission. 